\title{
Knowledge and Perceptions of COVID-19 among the General Public in Singapore: A Cross-sectional Online Survey
}

\section{Dear Editor,}

COVID-19 was declared a global pandemic on 11 March 2020 by the World Health Organization. ${ }^{1}$ Public health measures have been implemented all over the world ${ }^{2}$ to contain the spread of the severe acute respiratory syndrome coronavirus 2 (SARS-CoV-2). We conducted a study to assess the knowledge and perceptions of COVID-19 among the general public in Singapore. Understanding the public's awareness of COVID-19 will aid public health efforts towards containing COVID-19.

This is a cross-sectional study conducted via the FormsSG online survey platform. FormsSG is a free Singapore government online platform for data collection, which uses end-to-end encryption for data protection. It is also only accessible and administrated by governmentlinked institutions, with the assurance that such surveys are from official institutions. The study was based on volunteered responses, without monetary remuneration. The team from Alexandra Hospital disseminated the survey widely through an open call to the public via the National University Health System's social media channels. The online questionnaire was made available from 14 May 2020 to 21 May 2020. The survey comprised 11 questions on knowledge and perceptions of COVID-19, based on Singapore guidelines retrieved from the Ministry of Health $(\mathrm{MOH})$, Singapore website available on 1 April 2020. This study was approved by the National Healthcare Group ethics committee (DSRB reference number 2020/00396).

Statistical analysis was carried out using SPSS Statistics software version 25 (IBM Corp, Armonk, US). Categorical and continuous variables were analysed.

In total, 1,261 adults above 21 years old residing in Singapore completed the questionnaire. Respondents' basic demographic characteristics are summarised in Table 1.

The survey findings are summarised in Table 2. Questions 1 to 6 assessed the respondents' information-gathering habits, perceptions of the COVID-19 outbreak, and their degree of confidence in healthcare staff in containing the outbreak. Most respondents (88\%) checked for updates
Table 1. Basic demographic characteristics of survey participants (total participants $n=1,261$ )

\begin{tabular}{ll}
\hline Basic demographic characteristics & n (\%) \\
\hline Gender & \\
- Female, n (\%) & $707(56)$ \\
- Male, n (\%) & $554(44)$ \\
Age (in years) & \\
- $21-30$ & $288(22.8)$ \\
- $31-40$ & $248(19.6)$ \\
- $41-50$ & $211(16.7)$ \\
- 51-60 & $343(27,2)$ \\
- $61-70$ & $145(11,5)$ \\
- >70 & $26(2.2)$ \\
Education & \\
- Primary School Leaving Examination & \\
- GCE O-Level or equivalent & $10(0.8)$ \\
• GCE A-Level or equivalent & $148(11.7)$ \\
- Degree & $228(18.1)$ \\
- Postgraduate & $666(52.8)$ \\
\hline
\end{tabular}

on COVID-19 at least once a day. Most respondents (73\%) looked up reputable online news sites such as the BBC and CNA for COVID-19 updates, with a sizeable $49 \%$ also relying on WhatsApp application. Most respondents (92\%) indicated that individuals should continue to wear masks outdoors even after the easing of partial lockdown. Most respondents (80\%) had confidence in the long-term supply and quantity of masks and protective equipment for healthcare workers; and more than $85 \%$ supported various public health measures and advisories issued by the Singapore government and practised around the world. Questions 7 to 11 tested respondents' knowledge based on the then available guidelines and the COVID-19 outbreak situation in Singapore between April and May 2020.

The mode age range of the sampled population was 51-60 years while the median was in the $41-50$ years age group. The median age of Singapore in 2019 was 41.1 years. $^{3}$ While digital surveys tend to attract younger, more technologically savvy respondents, it is likely that the high public health interest in COVID-19 led to an equally robust response from older age groups. Misinformation through social media is concerning ${ }^{4}$ 
and can amplify public fear and panic, which are counterproductive during a pandemic. The top source of COVID-19 updates was online news (accessed by $73 \%$ of respondents) - the public may look upon these online news outlets as reliable sources of information. These findings would also help public health authorities prioritise their channels of communication when disseminating information. The use of WhatsApp was also common in our surveyed population with $49 \%$ of respondents having accessed it for updates. Of note, the Singapore government has also widely publicised an official Gov.sg WhatsApp channel as a way to disseminate factual COVID-19 updates. This may have led to similar proportion of respondents using both WhatsApp and MOH's official website as sources of updates. Updates via newspapers were accessed by $36 \%$ of respondents. This may reflect the increasing proliferation of digital news media, in hand with the likelihood that the respondents of the online survey would also use digital rather than print media. The public demonstrated good confidence that the outbreak can be contained - this is heartening as the public's confidence and adherence to health policies can be critical in outbreak containment. On 14 May 2020, when the survey was released, the number of infected cases worldwide was $4,248,389$, of which 292,046 had resulted in death, ${ }^{5}$ bringing the estimated case fatality rate (CFR) to $6.8 \%$. The public's estimate of the COVID-19 CFR was varied: $36 \%$ of respondents estimated $<3 \%$, while $34 \%$ estimated $3-7 \%$. This is in keeping with the difficulties in estimating the true CFR. ${ }^{6}$ As of 12 September 2020, the CFR within Singapore is $0.047 \%$ (27 deaths, 57,315 total infected cases). The low CFR in Singapore compared to worldwide statistics ${ }^{7}$ may have influenced the public's estimation of figures. The correct answer rate for knowledge-testing questions 7 to 11 was 76-94\% (Table 2).

Table 2. Summary of survey findings (total participants, $n=1,261$ )

\begin{tabular}{|c|c|}
\hline Survey questions and response options & n $(\%)$ \\
\hline $\begin{array}{l}\text { 1. How often do you check for updates on COVID-19? } \\
\text { - Seldom } \\
\text { - A few times a week } \\
\text { - Once a day } \\
\text { - Multiple times a day }\end{array}$ & $\begin{array}{l}39(3) \\
117(9) \\
689(55) \\
416(33)\end{array}$ \\
\hline $\begin{array}{l}\text { 2. Where do you get your updates on COVID-19 from? (multiple selections allowed) } \\
\text { - Reputable online news outlets e.g. British Broadcasting Corporation (BBC), Cable News Network (CNN), } \\
\text { - Channel NewsAsia (CNA) } \\
\text { - WhatsApp application } \\
\text { - Newspapore Ministry of Health's official website } \\
\text { - Facebook } \\
\text { - Non-mainstream media sources e.g. Mothership.sg, ricemedia.co } \\
\text { - Telegram application } \\
\text { - YouTube } \\
\text { - Twitter }\end{array}$ & $\begin{array}{l}925(73) \\
617(49) \\
592(47) \\
458(36) \\
407(32) \\
267(21) \\
223(18) \\
99(8) \\
25(2)\end{array}$ \\
\hline $\begin{array}{l}\text { 3. On a scale of } 1-5 \text {, where } 5 \text { indicates you are extremely concerned and } 1 \text { indicates you are not concerned at all, how } \\
\text { concerned are you about a food shortage in Singapore? }\end{array}$ & Mean $2.9 \pm 1.3$ \\
\hline $\begin{array}{l}4 \text { On a scale of } 1-5 \text {, with } 5 \text { being very socially responsible and } 1 \text { being very socially irresponsible, how well do you } \\
\text { think the public is in terms of being socially responsible? }\end{array}$ & Mean $3.4 \pm 0.9$ \\
\hline $\begin{array}{l}\text { 5. Do you think people should wear masks when going outside even after partial lockdown ends? } \\
\text { - No } \\
\text { - Yes }\end{array}$ & $\begin{array}{l}104(8) \\
1157(92)\end{array}$ \\
\hline $\begin{array}{l}\text { 6. Do you think Singapore has enough masks and protective equipment in the long term for healthcare workers? } \\
\text { - No } \\
\text { - Yes }\end{array}$ & $\begin{array}{l}256(20) \\
1005(80)\end{array}$ \\
\hline 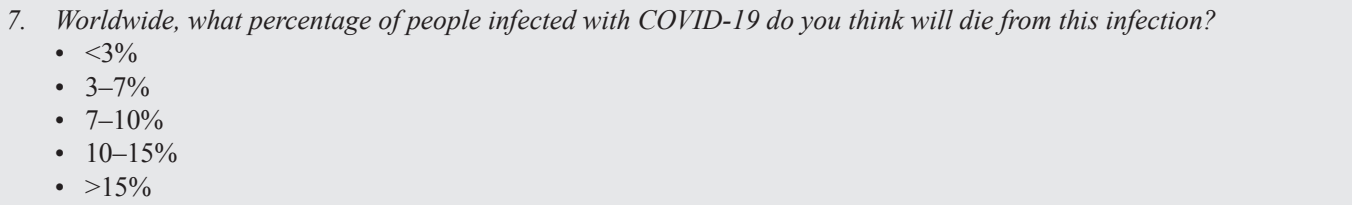 & $\begin{array}{l}455(36) \\
429(34) \\
183(15) \\
119(9) \\
75(6)\end{array}$ \\
\hline
\end{tabular}


Table 2. Summary of survey findings (total participants, $n=1,261$ ) (Cont'd)

\begin{tabular}{|c|c|c|}
\hline \multicolumn{2}{|r|}{ Survey questions and response options } & n (\%) \\
\hline 8. & $\begin{array}{l}\text { Which of the following populations is/are more susceptible to complications and mortality from COVID-19? } \\
\text { (multiple selections allowed) } \\
\text { - Children }<18 \text { years of age } \\
\text { - Adults } 18-64 \text { years of age } \\
\text { - Adults with }>2 \text { chronic medical conditions e.g. diabetes, hypertension, cancer, stroke, etc. } \\
\text { - Elderly }>64 \text { years of age } \\
\text { - Elderly with }>2 \text { chronic medical conditions e.g. diabetes, hypertension, cancer, stroke, etc. }\end{array}$ & $\begin{array}{l}121(10) \\
73(6) \\
844(67) \\
930(74) \\
1185(94)\end{array}$ \\
\hline 9. & $\begin{array}{l}\text { What do you think are the top } 3 \text { most common signs and symptoms experienced by COVID-19 patients? } \\
\text { - Fever } \\
\text { - Dry cough } \\
\text { - Shortness of breath } \\
\text { - Rure throat } \\
\text { - Lethargy nose } \\
\text { - Muscle aches (myalgia) } \\
\text { - Diarrhoea } \\
\text { - Headaches } \\
\text { - Rash } \\
\text { - Nosebleed } \\
\text { - Constipation }\end{array}$ & $\begin{array}{l}1144(91) \\
908(72) \\
788(62) \\
520(41) \\
196(16) \\
150(12) \\
58(5) \\
54(4) \\
49(4) \\
4(0.3) \\
0(0) \\
0(0)\end{array}$ \\
\hline 10. & $\begin{array}{l}\text { What do you think is the main route of community transmission of COVID-19? } \\
\text { - Airborne } \\
\text { - Droplets } \\
\text { - Faecal-oral } \\
\text { - Sexual transmission }\end{array}$ & $\begin{array}{l}212(17) \\
955(76) \\
93(7) \\
1(<0.1)\end{array}$ \\
\hline & $\begin{array}{l}\text { Which of the following actions do you think will help with preventing the spreading of COVID-19? } \\
\text { - Frequent washing of hands/use of alcohol hand sanitisers } \\
\text { - Abiding by social distancing rules of keeping a distance from people at all times } \\
\text { - Avoid touching of face with unwashed hands } \\
\text { - Avoiding close contact with people who are sick } \\
\text { - Wearing a face mask when out at all times } \\
\text { - Staying home and not working if unwell } \\
\text { - Avoiding going out unnecessarily } \\
\text { - Avoiding visits to the hospital unless necessary } \\
\text { - Keeping childcare and eldercare centres closed } \\
\text { - Avoid close contact with healthcare workers }\end{array}$ & $\begin{array}{l}1199(95) \\
1119(89) \\
1110(88) \\
1099(87) \\
1069(85) \\
1062(84) \\
991(79) \\
841(67) \\
371(30) \\
181(14)\end{array}$ \\
\hline
\end{tabular}

Based on our information, this is the first study exploring the knowledge and perceptions of COVID-19 in Singapore, which was done nearly 4 months after the first COVID-19 case was detected in the country. The survey was also conducted when Singapore was more than 5 weeks into a partial lockdown, which was imposed nationwide to control the exponential rise of COVID-19 cases. The vast majority (92\%) supported the wearing of masks when going out, which has been made compulsory since 15 April 2020. This likely reflects changing mindsets and attitudes about maskwearing, and a heightened sense of personal hygiene and social responsibility. High COVID-19 knowledge was reflected in the high correct answer rates. A study by Zhong et al. ${ }^{8}$ performed among residents in China reflected that high knowledge was associated with a lower likelihood of having misconceptions, and exhibiting uninformed and dangerous personal/ community practices.

This study's strengths include a relatively large recruitment sample size, with a fairly heterogenous group of respondents. However, its limitations include the under-representation of older adults aged 70 and above. This could be due to limitations in literacy levels, and access to technology and social networks through which the survey was disseminated. Most respondents have received tertiary education, which may also limit the generalisability of the results. The survey was based on volunteer response, which may have led to unintentional sampling bias.

To conclude, support for public health measures is high among the tertiary-educated demographic in Singapore. Consistent implementation of good hygiene practices and public health measures across the 
population will likely yield results in the long-term containment of COVID-19.

\section{REFERENCES}

1. World Health Organization. Coronavirus disease (COVID-19) situation reports. Available at: https:/www.who.int/emergencies/ diseases/novel-coronavirus-2019/situation-reports. Accessed on 25 May 2020.

2. Fisher D, Wilder-Smith A. The global community needs to swiftly ramp up the response to contain COVID-19. Lancet 2020;395:1109-10.

3. Singapore Department of Statistics. Population and Population Structure. Available at: https://www.singstat.gov.sg/find-data/searchby-theme/population/population-and-population-structure/latest-data. Accessed on 25 May 2020.

4. Depoux A, Martin S, Karafillakis E, et al. The pandemic of social media panic travels faster than the COVID-19 outbreak. J Travel Med 2020;27:taaa031.

5. World Health Organization. Situation Report - 115, 14 May 2020. Available at: https://www.who.int/docs/default-source/ coronaviruse/situation-reports/20200514-covid-19-sitrep-115. pdf?sfvrsn=3fce8d3c_6. Assessed on 14 May 2020.
6. Rajgor DD, Lee MH, Archuleta S, et al. The many estimates of the COVID-19 case fatality rate. Lancet Infect Dis 2020;20:776-7.

7. Chew SY, Lee YS, Ghimiray D, et al. Characteristics and Outcomes of COVID-19 Patients with Respiratory Failure Admitted to a "Pandemic Ready" Intensive Care Unit - Lessons from Singapore. Ann Acad Med Singap 2020;49:434-48.

8. Zhong BL, Luo W, Li HM, et al. Knowledge, attitudes, and practices towards COVID-19 among Chinese residents during the rapid rise period of the COVID-19 outbreak: a quick online cross-sectional survey. Int J Biol Sci 2020;16:1745-52.

Valencia Long, ${ }^{1}{ }_{M B B S,}$ MMed, $M R C P$,

Benjamin Yee San $\underline{\operatorname{Tan}}{ }^{1}{ }_{M B B S}$, Li Feng Tan ${ }^{1}{ }_{M B B S, ~ M M e d, ~ M R C P}$

${ }^{1}$ Healthy Ageing Programme, Alexandra Hospital, Singapore

Address for Correspondence: Dr Li Feng Tan, Alexandra Hospital, 378 Alexandra Rd, Singapore 159964.

Email: li_feng_tan@nuhs.edu.sg 